\title{
Zinc Regarding the Utilization of Waste Tires by Pyrolysis
}

\author{
Anna Ilnicka ${ }^{1}$, Jarosław Okonski ${ }^{1}$, Aleksandra W. Cyganiuk ${ }^{1}$, \\ Jaromir Patyk ${ }^{2}$, Jerzy P. Lukaszewicz ${ }^{1,2 *}$ \\ ${ }^{1}$ Faculty of Chemistry, Nicolaus Copernicus University, \\ Gagarina 7, 87-100 Torun, Poland \\ ${ }^{2}$ Centre for Modern Interdisciplinary Technologies ICNT, \\ Wilenska 4, 87-100 Toruń, Poland
}

Received: 24 April 2015

Accepted: 7 March 2016

\begin{abstract}
The major goal of our study was to demonstrate how to eliminate zinc from the products of waste tire pyrolysis and avoid its environmental circulation. The new tire utilization manner consists of a separate combustion of the pyrolytic char containing $5.1 \mathrm{wt}$. \% zinc and a collection of such obtained ash $(10.4 \%$ yield) that contains $42 \mathrm{wt}$ \% of zinc. The ash is a good candidate for metallurgical recovery of metallic zinc. The study demonstrates that pyrolytic char, because of its very low BET surface area of $43-60 \mathrm{~m}^{2} / \mathrm{g}$, should not be transformed into activated carbon. High surface areas reported in literature $\left(800-910 \mathrm{~m}^{2} / \mathrm{g}\right)$ for some pyrolytic chars were achieved after a complex and expensive activation process. Moreover, the study proved that zinc derivatives in tire-driven pyrolytic chars could be released to the environment since they were partly leached in $\mathrm{H}_{2} \mathrm{O}$ and etched in $0.1 \mathrm{M} \mathrm{HCl}$ solution. The study demonstrates that zinc can be eliminated from environmental circulation during tire pyrolysis and proposed an alternative solution to the transformation of pyrolytic char into activated carbon.
\end{abstract}

Keywords: tire, pyrolysis, activated carbon, zinc recovery

\section{Introduction}

Waste rubber and particularly waste automobile tires present a serious ecological problem. Various sources estimate that the global annual production of new tires exceeds 1,000 million units [1]. It is obvious that after a period of exploitation, a similar quantity of waste rubber material should be used because the natural decay of rubber is estimated to take 50-100 years [2]. In addition

*e-mail: lukaszju@chem.uni.torun.pl to the ecological aspects of waste tire utilisation, it should be remembered that the significant mass of rubber has real economic value and that millions of tons of potentially valuable chemicals become "frozen" every year. Therefore, several methods for the utilisation of this resource are introduced every day. Perhaps the most controversial is the burning of waste tires in the cement industry [2-3]. The controversy results from the emission of hazardous products of combustion, such as zinc derivatives, hydrocarbons, carbon oxides, sulphur oxides, and the loss of the steel components of the tires (steel belts), which could be recovered [4]. 
In the past two decades, new facilities for the utilization of waste tires have developed throughout the world. These installations apply thermal decomposition (pyrolysis) to waste tires. The method yields three basic products: flammable gas (up to $11 \mathrm{wt}$ \%), liquid oil (i.e., a mixture of hydrocarbons resembling a natural crude oil - up to 50 wt. \%), and a solid char (up to 46 wt. \%) [5]. The first product may be used at the location of tire pyrolysis for the production of heat, steam, or electricity. The oil may serve as a fuel but may also be subjected to advanced chemical treatments, such as distillation, desulphurisation, and catalytic conversion [6]. The solid product of pyrolysis seem to be a type of ballast because its utilisation is the most complex. The high yield of the solid product (char) calls into question the entire concept of tire pyrolysis because the demand for the unconverted char is very limited. The most critical opinions state that tire pyrolysis converts one kind of waste into another. Thus, a reasonable (environmentally friendly and cost-effective) transformation of the char is a real and growing problem. Some utilization methods rely on the transformation of the char into typical carbon-based products: activated carbon (adsorbent) and carbon black (adsorbent and filler) [7-11]. The raw char has very unsatisfactory structural parameters of specific surface area, total pore volume, and pore structure. These properties must be upgraded before applying the char as an adsorbent and for this, several conventional activation methods have been applied $\left(\mathrm{CO}_{2}\right.$ activation, steam activation) [7]. However, there is almost nothing mentioned in the literature regarding the costs of such transformations. Furthermore, previously published reports do not consider the problem of the residual constituents of the tire rubber such as zinc oxide $\mathrm{ZnO}$ (an activator in the vulcanisation process).

The $\mathrm{ZnO}$ content in automobile tires ranges from 1 to 3 wt. \%. Neither the volatilised nor the liquefied products of tire pyrolysis contain considerable amounts of zinc derivatives because $\mathrm{ZnO}$ is a relatively stable, inert, and non-volatile substance.

The aim of our study is to examine the zinc (and its derivatives) pathway from waste tire rubber to the solid product of tire pyrolysis, and to estimate the possibility of zinc recovery from the char.

\section{Materials and Methods}

Scrap tires were pyrolysed in an industrial installation for waste tire pyrolysis (EkoCeramika, Torun, Poland). Such obtained char was investigated in this study. $41.222 \mathrm{~g}$ of delivered char was subjected to a heat treatment in argon at $1,000^{\circ} \mathrm{C}$ in a tubular furnace for $3 \mathrm{~h}$, while $35.611 \mathrm{~g}$ of char was combusted to ash in a tubular furnace at $900^{\circ} \mathrm{C}$ in a stream of air (free access to oxygen). The ash after combustion was collected and weighed. The elemental composition of the char and the ash was performed using the SEM-EDS method with $0.25 \%$ accuracy as declared by the apparatus manufacturer (Scanning Electron Microscope LEO 1430 VP equipped with an EDS detector Quantax 200 XFlash 4010 Bruker). Final results on elemental contents gained by SEM-EDS were calculated as an average of five subsequent measurements (acquisition time $120 \mathrm{~s}$ ). Additionally, certain amounts of the collected ash (Table 1) were subjected to leaching in water (200 $\mathrm{cm}^{3}$ water, $24 \mathrm{~h}$ stirring, room temperature) and etching in $0.1 \mathrm{M} \mathrm{HCl}$ solution $\left(200 \mathrm{~cm}^{3}\right.$ water, $24 \mathrm{~h}$ stirring, room temperature).

Specific surface area and pore structure of the char were investigated by means of the low temperature nitrogen adsorption method (Micrometitics ASAP 2010 sorptomat). Primary nitrogen adsorption data were regressed using the BET method to obtain specific surface area of investigated char samples.

\section{Results and Discussion}

Firstly, we assumed that $\mathrm{ZnO}$ in pure form, or as another zinc derivative, should pass qualitatively to the solid product of pyrolysis, i.e., the char. If $100 \mathrm{~kg}$ of waste tire rubber is pyrolysed, the $\mathrm{ZnO}$ content is $1-2 \mathrm{wt}$. $\%$ (standard content) and the average char yield is $40 \%$ to $50 \%$ (of the tire mass). Therefore, the $\mathrm{ZnO}$ content in the char should approach 2-5 wt. \% (pure zinc content ca. 1.6-4.0 wt. \%). This theoretical assumption was verified experimentally. The value $\mathrm{Zn}_{\mathrm{b}}$ [wt. \%] (Table 1) means an experimentally determined content of zinc in the char obtained through tire pyrolysis. This value of $4.6 \mathrm{wt} . \%$

Table 1. Change of mass and zinc content upon performed treatments.

\begin{tabular}{|c|c|c|c|c|c|c|}
\hline Action & $\mathbf{M}_{\mathbf{b}}[\mathbf{g}]$ & $\mathbf{M}_{\mathbf{a}}[\mathbf{g}]$ & $\mathbf{M}_{\mathbf{d}}[\mathbf{\%}]$ & $\begin{array}{c}\mathbf{Z n}_{\mathbf{b}} \\
{[\mathbf{w t .} \% \mathbf{0}]}\end{array}$ & $\begin{array}{c}\mathbf{Z n}_{\mathbf{a}} \\
\text { [wt. \%] }\end{array}$ & $\begin{array}{c}\mathbf{Z n}_{\mathbf{s}} \\
\text { [wt. \%] }\end{array}$ \\
\hline Char combustion & 35.6 & 3.7 & 89.6 & $\begin{array}{c}4.60 \\
\text { (in char) }\end{array}$ & $\begin{array}{c}42.02 \\
\text { (in ash) }\end{array}$ & 5.10 \\
\hline Ash leaching in water & 1.138 & 0.840 & 26.2 & $\begin{array}{c}42.02 \\
\text { (in ash) }\end{array}$ & $\begin{array}{c}24.35 \\
\text { (in ash) }\end{array}$ & 42.05 \\
\hline Ash etching in 0.1M HCl & 0.788 & 0.451 & 42.8 & $\begin{array}{c}24.35 \\
\text { (in ash) }\end{array}$ & $\begin{array}{c}14.85 \\
\text { (in ash) }\end{array}$ & 39.01 \\
\hline $\begin{array}{c}\text { Ash leaching in water and subsequent etching in } \\
\text { 0.1M HCl }\end{array}$ & - & - & 57.7 & - & - & 64.66 \\
\hline
\end{tabular}

$\mathbf{M}_{\mathbf{b}}$ mass before the action, $\mathbf{M}_{\mathbf{a}}$ mass after the action, $\mathbf{M}_{\mathbf{d}}$ mass decrease upon the action, $\mathbf{Z} \mathbf{n}_{\mathrm{b}}$ zinc content before the action, $\mathbf{Z} \mathbf{n}_{\mathrm{a}}$ zinc content after the action, $\mathbf{Z} \mathbf{n}_{\mathrm{s}}$ amount of zinc released to solution upon the action 
is even better than the theoretical estimation presented above, i.e., 1.6-4.0 wt. \%.

As post-pyrolytic chars are often seen as the precursor for activated carbon fabrication, we performed experiments involving the heating of the char (inert gas atmosphere) to simulate the conditions required by some activation procedures [7]. Table 2 presents the weight content of some elements in the post-pyrolytic char heattreated at $1000^{\circ} \mathrm{C}$ for $3 \mathrm{~h}$. It can also be seen that a single heat treatment does not improve by much the structural parameters of the heat-treated char. We observed that the BET surface area increased very little upon heat treatment from 43 to $60 \mathrm{~m}^{2} / \mathrm{g}$. However, the heat treatment changed the elemental composition of the char. The content of carbon increased $(72.9 \% \rightarrow 80.4$ wt. $\%)$ while the content of oxygen decreased (16.1 wt. $\% \rightarrow 13.6$ wt. \%). This is understandable because pyrolytic chars usually contain plenty of carbon-oxygen species whose thermal stability is limited to $900-1000^{\circ} \mathrm{C}$.

Upon heat treatment, the species decomposed. It was also found that the weight content of zinc decreased from $4.7 \%$ to 0.8 wt. $\%$. As expected, the value in the postpyrolysis char was definitely higher ( $4.7 \%$ of zinc) than the average content in the automobile tires ( $1 \%$ to $2 \% \mathrm{ZnO})$. The decrease of zinc content due to the heat treatment at elevated temperatures $\left(1000^{\circ} \mathrm{C}\right.$ in argon $)$ is caused by the well-known reduction of zinc ions in the non-oxidative atmosphere and the presence of a carbon matrix:

$$
\begin{gathered}
\mathrm{ZnO}+\mathrm{C}_{\text {matrix }} \rightarrow \mathrm{Zn}^{\circ}+\mathrm{CO} \\
\mathrm{ZnO}+\mathrm{CO} \rightarrow \mathrm{Zn}^{\mathrm{o}}+\mathrm{CO}_{2}
\end{gathered}
$$

At a temperature of $1000^{\circ} \mathrm{C}$, vaporisation of zinc is very intense because the melting point of the metal is $907^{\circ} \mathrm{C}$. The high volatility of zinc is exploited practically in the industrial production of metallic zinc, where zinc ore (containing $\mathrm{ZnO}$ ) is heated in the presence of coke, and metallic zinc evolves as a vapour. We compared our results to another study presented in the literature [10-13], which confirmed the high zinc content in the bare postpyrolysis char from tires (4.2 wt. \%). In that case, the char was activated by heat treatment at a lower temperature of $900^{\circ} \mathrm{C}$ (in argon) and the zinc reduction and volatilisation was less intense than at $1000^{\circ} \mathrm{C}$ (our research). In the cited study, zinc and its derivatives were removed effectively by etching the activated (heat-treated) and non-activated (bare) post-pyrolytic chars in acids $\left(\mathrm{HCl}\right.$ and $\left.\mathrm{H}_{2} \mathrm{SO}_{4}\right)$. The removal of zinc by the $\mathrm{HCl}$ treatment was almost complete (from $4.2 \% \rightarrow 0.6 \mathrm{wt}$. $\%$ for the bare char), whereas for the $\mathrm{H}_{2} \mathrm{SO}_{4}$ treatment, the removal was less complete (from $4.2 \% \rightarrow 2.9 \mathrm{wt}$. $\%$ for the bare char). The effect is understandable because the action of the $\mathrm{HCl}$ transforms zinc derivatives into a soluble salt $\mathrm{ZnCl}_{2}$ (in water). The action of the $\mathrm{H}_{2} \mathrm{SO}_{4}$ led to the formation of much less soluble $\mathrm{ZnSO}_{4}$. A similar effect was observed in the case of calcium derivatives in the char; $\mathrm{HCl}$ removed calcium totally $\left(\mathrm{CaCl}_{2}\right.$ is water soluble), whereas the action of $\mathrm{H}_{2} \mathrm{SO}_{4}$ was only moderately effective $\left(\mathrm{CaSO}_{4}\right.$ is nonsoluble in water). Thus, a transformation of post-pyrolysis char into an active carbon is very often connected with the emission of zinc, either as metal vapours and/or the transfer of zinc into the etching liquids, such as $\mathrm{HCl}$ and $\mathrm{H}_{2} \mathrm{SO}_{4}$.

Table 2 proves that the sulphur content in the investigated char is low. Additionally, our XRD investigations did not reveal the presence of $\mathrm{ZnS}$ in the char, as found in other studies [11-13]. High content of sulphur (also as $\mathrm{ZnS}$ ) could considerably limit the utilization of such a sulphur-rich char by combustion. However, the quoted study applied a microwave-based decomposition of tires, whose mechanism should be considered substantially different from the traditional pyrolysis applied in this study.

We tried to verify what might happen if the char produced in the process of waste tire pyrolysis was

\begin{tabular}{|c|c|c|c|c|c|c|c|}
\hline \multirow{2}{*}{ Sample } & \multirow{2}{*}{$\begin{array}{c}\mathrm{S}_{\mathrm{BET}} \\
{\left[\mathrm{m}^{2} / \mathrm{g}\right]}\end{array}$} & \multicolumn{6}{|c|}{ Content of major elements [wt. \%] } \\
\hline & & $\mathbf{C}$ & $\mathbf{O}$ & $\mathbf{S i}$ & $\mathbf{S}$ & $\mathbf{Z n}$ & $\mathbf{C a}$ \\
\hline \multicolumn{8}{|c|}{ Results presented by $[8]$} \\
\hline Bare char & 85 & 83.1 & 6.0 & 1.6 & 2.6 & 4.6 & 2.4 \\
\hline Bare char etched in $\mathrm{HCl}$ & 870 & 93.0 & 5.1 & 0.4 & 0.9 & 0.6 & - \\
\hline Activated char etched in $\mathrm{HCl}$ & 940 & 93.9 & 4.3 & 0.4 & 0.8 & 0.6 & - \\
\hline Bare char etched in $\mathrm{H}_{2} \mathrm{SO}_{4}$ & 800 & 87.0 & 5.9 & 0.6 & 1.8 & 2.9 & 1.8 \\
\hline Activated char etched in $\mathrm{H}_{2} \mathrm{SO}_{4}$ & 910 & 90 & 4.4 & 0.6 & 1.2 & 2.0 & 1.8 \\
\hline \multicolumn{8}{|c|}{ This study results } \\
\hline Bare char & 43 & 72.9 & 16.1 & 2.0 & 2.8 & 4.7 & 1.3 \\
\hline $\begin{array}{c}\text { Bare char heat-treated at } \\
1,000^{\circ} \mathrm{C} \text { in argon }\end{array}$ & 60 & 80.4 & 13.6 & 2.1 & 1.5 & 0.8 & 1.3 \\
\hline
\end{tabular}

Table 2. Specific surface area and elemental composition of bare and activated chars: a comparison of literature and our own results. 
Table 3. Elemental composition of ash.

\begin{tabular}{|c|c|c|c|c|c|c|c|c|c|c|}
\hline & \multicolumn{10}{|c|}{ Element } \\
\hline & $\mathrm{C}$ & $\mathrm{O}$ & $\mathrm{Al}$ & $\mathrm{Si}$ & S & $\mathrm{K} / \mathrm{Na}$ & $\mathrm{Ca} / \mathrm{Mg}$ & $\mathrm{Fe}$ & $\mathrm{Zn}$ & $\Sigma$ \\
\hline & \multicolumn{10}{|c|}{ [wt. \%] } \\
\hline Bare ash & 4.8 & 25.26 & 1.32 & 6.88 & 2.45 & 7.87 & 6.65 & 2.59 & 42.02 & 99.81 \\
\hline After leaching in $\mathrm{H}_{2} \mathrm{O}$ & 10.15 & 41.87 & 4.10 & 10.22 & 0.13 & 0.19 & 2.56 & 2.84 & 24.35 & 96.41 \\
\hline $\begin{array}{c}\text { After leaching in } \\
\mathrm{HCl} \text { and etching in } 0.1 \mathrm{M} \mathrm{HCl}\end{array}$ & 6.72 & 37.42 & 6.13 & 17.18 & - & 0.42 & 1.21 & 3.07 & 14.85 & 87.00 \\
\hline Direction of changes & ? & $\Delta$ & $\boldsymbol{\Delta}$ & $\Delta$ & $\boldsymbol{\nabla}$ & $\nabla$ & $\boldsymbol{\nabla}$ & $\Delta$ & $\boldsymbol{\nabla}$ & $\nabla$ \\
\hline
\end{tabular}

treated as fuel. A weighed amount of char (35.611 g) was placed in a tubular furnace. A temperature of $900^{\circ} \mathrm{C}$ was maintained for $1 \mathrm{~h}$ and free access of air was provided to create oxidative conditions. The ash (3.709 g) was cooled, weighed, and analysed using the SEM-EDS method to determine its elemental composition (Tables 1-3). The ash consisted mainly of zinc (42.0 wt. \%) and oxygen (25.3 wt. \%). The values obtained permitted a calculation of the effectiveness of the zinc transfer from char to ash. The amount of burned char (35.6 g) contained $4.6 \mathrm{wt}$. $\%$ elemental zinc, which is equal to $1.638 \mathrm{~g}$ (calculated value). The amount of collected ash $(3.7 \mathrm{~g})$ contained 42 wt. \% elemental zinc, which is equal to $1.554 \mathrm{~g}$ (calculated value). Thus, the effectiveness of the zinc transfer from char to ash during burning can be calculated as follows: $1.554 / 1.638 \times 100 \%=94.9 \%$. The losses (i.e., emissions to the environment) were minor. The previously described evaporation of metallic zinc (Table 1) occurred in oxygen-free conditions, in which zinc derivatives were reduced to metallic zinc and evaporated from the heattreated char. In the case of char combustion, the oxidative conditions prevented the reduction of zinc, retaining it in non-volatile forms. Therefore, the transfer of zinc to ash was almost complete. This means that the ash obtained from post-pyrolytic char is a zinc concentrate, which potentially can be applied in a metallurgical processes leading to metallic zinc fabrication.

As mentioned, the collected ash is a potential source of zinc for metallurgical conversion, but it is also a source of environmental pollution. The latter situation may involve the release of zinc ions to a solution of differentiated $\mathrm{pH}$. A release of zinc ions to the environment was simulated by treating the ash with water (leaching with an excess of distilled water at room temperature with temporary stirring for $24 \mathrm{~h}$ ) and subsequently treating it with diluted mineral acid (etching with an excess of $0.1 \mathrm{M} \mathrm{HCl}$ solution at room temperature with temporary stirring for $24 \mathrm{~h}$ ). Each action led to a substantial release of zinc (Table 1). In summary, both actions (leaching and etching) reduced the zinc content in the water/acid-treated ash spectacularly and delivered zinc ions in considerable quantities to the environment, even through contact with water. Therefore, the ash originating from waste tire char has to be collected in case the char is burned. The burning of such chars may occur in two situations:
- As a method for the utilisation of activated carbon (used as an adsorbent) received from raw postpyrolytic chars by a suitable activation method.

- As a method for the utilisation of raw post-pyrolytic chars obtained directly from tire pyrolysis without any additional activation.

The latter situation is a real alternative to any transformation of char to active carbon, because the entire concept of active carbon production from waste tires seems to be controversial. There are a number of reasons for this:

- The complexity of the known transformation methods and expected high costs.

- The proven partial reduction and evaporation of zinc during high-temperature treatment, which is usually required by activation procedures.

- High zinc content in activated carbon obtained from post-pyrolytic char. Such activated carbon has to be utilised with care regarding the release of zinc to the environment, and thus leaching/etching should be prevented.

Table 3 presents the results of the elemental composition of bare ash and the ash leached with water and etched in $0.1 \mathrm{M} \mathrm{HCl}$. Upon leaching and etching, the ash contained reduced quantities of zinc, alkaline metals, alkaline earth metals, and sulphur. Thus zinc in the ash from post-pyrolytic chars was present mostly in water/acid soluble forms. Alkaline and alkaline metal derivatives are in most water/acid soluble species; therefore, their content decreased following the treatments. In contrast, aluminium, silicon, and iron were present in the ash in water/acid nonsoluble forms. Therefore, their content increased in the leached/etched ash following the removal of the soluble components. X-ray diffraction investigations revealed that following the leaching/etching, the ash contained nonsoluble species, such as $\mathrm{SiO}_{2}, \mathrm{Al}_{2} \mathrm{O}_{3}$, and non-soluble zinc derivatives (the treated ash still contained ca. $14 \mathrm{wt}$ \% of zinc).

The overall pyrolysis process, including a separate burning of char, will deliver two conventional products (pyrolytic gas to be burned on spot, pyrolytic oil for further chemical or energetic usage) and two new products (heat and/or electric energy from the burning of pyrolytic char and zinc concentrate for the metallurgical industry). Moreover, the modified process is finally free from an embarrassing by-product, i.e., pyrolytic char. 


\section{Conclusion}

The new finding of this study is to apply raw postpyrolytic chars as a highly energetic fuel (heat of combustion ca. $35 \mathrm{MJ} / \mathrm{kg}$ ) for the production of heat and/or electrical energy, which is more reasonable than converting them into activated carbon. Such chars should be burned separately with an excess of oxygen in heat/ electricity generators, but the resulting ash must be collected. This ash, because of the very high zinc content, may serve as a raw material for metallurgical conversion to metallic zinc. The presented concept could lead to the annual recovery of thousands of tons of zinc and/or its derivatives and eliminate them from the environment. The presented concept is up-to-date the sole scenario leading to the elimination of zinc from waste tire utilization by pyrolysis and preventing its further environmental circulation.

\section{References}

1. WILLIAMS P.T. Waste Treatment and Disposal, $1^{\text {st }}$ ed.; John Wiley and Sons Ltd., Chichester, 2005.

2. GRONOWICZ J., KUBIAK T. Recycling of used automobile tires. Problemy Eksploatacji 2, 5, 2007 [in Polish].

3. NAKAJIMA Y., MATSUYUKI M. Utilization of waste tires as fuel for cement production. Conserv. Recycl 4, 145, 1981.
4. CARRASCO F., BREDIN N., HEITZ M. Contaminant emissions as affected by burning scrap tires in cement manufacturing. J. Environ. Qual. 31, 1484, 2002.

5. BAJUS M., OLAHOVÁ N. Thermal conversion of scrap tires, Pet. Coal 53, 98, 2011.

6. TRONGKAEW T., UTISTHAM T., REUBROYCHAROEN P., HINCHIRANAN N. Photocatalytic desulfurization of waste tire pyrolysis oil. Energies 4, 1880, 2011.

7. MUI E.L.K., KO D.C.K., MCKAY G. Production of active carbons from waste tires - a review. Carbon 42, 2789, 2004.

8. BETANCUR M., MARTÍNEZ J.D., MURILLO R. Production of activated carbon by waste tire thermochemical degradation with $\mathrm{CO}_{2}$. J. Hazard. Mater. 168, 882, 2009.

9. BARAL D.R., JHA V.K. Preparation of activated charcoal adsorbent from waste tire. Sci. World 10, 80, 2012.

10. MARTÍNEZ J.D., MURILLO R., GARCÍA T. Production of carbon black from the waste tires pyrolysis. Boletin del Grupo Espanol de Carbon 30, 10, 2013.

11. MIKULOVA Z., SEDENKOVA I., MATEJOVA L., VECER M., DOMBEK V. Study of carbon black obtained by pyrolysis of waste scrap tires. J. Therm. Anal. Calorim. 111, 1475, 2013.

12. SHAH J., RASUL J., FAZAL M., SHAHID M. Conversion of waste tires into carbon black and their utilization as adsorbent. J. Chin. Chem. Soc. 53, 1085, 2006.

13. UNDRI A., SACCHI B., CANTISANI E., TOCCAFONDI N., ROSI L., FREDIANI M., FREDIANI P. Carbon from microwave assisted pyrolysis of waste tires. J. Anal. Appl. Pyrolysis 104, 396, 2013. 